\title{
Target Selectivity of Feedforward Inhibition by Striatal Fast-Spiking Interneurons
}

\author{
Susanne N. Szydlowski, ${ }^{\star}$ Iskra Pollak Dorocic, ${ }^{\star}$ Henrike Planert, ${ }^{\star}$ Marie Carlén, Konstantinos Meletis, \\ and Gilad Silberberg \\ Department of Neuroscience, Karolinska Institutet, Stockholm 17177, Sweden
}

The striatal microcircuitry consists of a vast majority of projection neurons, the medium spiny neurons (MSNs), and a small yet diverse population of interneurons. To understand how activity is orchestrated within the striatum, it is essential to unravel the functional connectivity between the different neuronal types. Fast-spiking (FS) interneurons provide feedforward inhibition to both direct and indirect pathway MSNs and are important in sculpting their output to downstream basal ganglia nuclei. FS interneurons are also interconnected with each other via electrical and chemical synapses; however, whether and how they inhibit other striatal interneuron types remains unknown. In this study we combined multineuron whole-cell recordings with optogenetics to determine the target selectivity of feedforward inhibition by striatal FS interneurons. Using transgenic and viral approaches we directed expression of channelrhodopsin 2 (ChR2) to FS interneurons to study their connectivity within the mouse striatal microcircuit. Optogenetic stimulation of ChR2-expressing FS interneurons generated strong and reliable $\mathrm{GABA}_{\mathrm{A}}$-dependent synaptic inputs in MSNs. In sharp contrast, simultaneously recorded neighboring cholinergic interneurons did not receive any synaptic inputs from photostimulated FS cells, and a minority of low-threshold spiking (LTS) interneurons responded weakly. We further tested the synaptic connectivity between FS and LTS interneurons using paired recordings, which showed only sparse connectivity. Our results show that striatal FS interneurons form a feedforward inhibitory circuit that is target selective, inhibiting projection neurons while avoiding cholinergic interneurons and sparsely contacting LTS interneurons, thus supporting independent modulation of MSN activity by the different types of striatal interneurons.

\section{Introduction}

Striatal and neocortical circuits share a common structural principle: a major projecting neuronal population interlaced with a small yet diverse interneuron population (Kawaguchi et al., 1995; Markram et al., 2004). One important and functionally distinct interneuron type, the fast-spiking (FS) interneuron, provides robust perisomatic inhibition to projection neurons in both striatal (Kita et al., 1990; Bennett and Bolam, 1994; Koós and Tepper, 1999; Gittis et al., 2010; Planert et al., 2010) and cortical (Somogyi et al., 1998; Gupta et al., 2000; Tamás et al., 2000) microcircuits. In the neocortex, recent studies have shown a seemingly unselective synaptic connectivity between FS interneurons and a vast majority of neighboring neocortical neurons of all types (Staiger et al., 1997; Gibson et al., 1999; Deans et al., 2001; Cruikshank et al., 2010; Gittis et al., 2010; Packer and Yuste, 2011; Avermann et al., 2012). Similarly, both direct and indirect pathway striatal

Received July 26, 2012; revised Nov. 24, 2012; accepted Dec. 5, 2012.

Author contributions: M.C., K.M., and G.S. designed research; S.N.S., I.P.D., H.P., and G.S. performed research; S.N.S., I.P.D., H.P., M.C., K.M., and G.S. analyzed data; S.N.S., H.P., K.M., and G.S. wrote the paper.

This study has been supported by National Alliance for Research on Schizophrenia and Depression Young Investigator grants (M.C. and K.M.), a Marie Curie European reintegration grant (K.M.), Knut och Alice Wallenberg Foundation (M.C. and K.M.), Hjärnfonden (M.C and K.M.), StratNeuro (G.S. and K.M.), and ERC starting grant (G.S.). We thank Karl Deisseroth for the ChR2-mCherry vector and Silvia Arber for the transgenic PV-Cre mice. We thank Abdel El Manira and Paul Bolam for comments on this manuscript.

*S.N.S., I.P.D., and H.P. contributed equally to this work.

Correspondence should be addressed to either of the following at the above address: Gilad Silberberg or Konstantinos Meletis. E-mail: gilad.silberberg@ki.se or dinos.meletis@ki.se.

DOI:10.1523/JNEUROSCI.3572-12.2013

Copyright $\odot 2013$ the authors $\quad 0270-6474 / 13 / 331678-06 \$ 15.00 / 0$ medium spiny neurons (MSNs) receive synaptic inputs from nearby FS interneurons (Gittis et al., 2010; Planert et al., 2010). FS interneurons are also interconnected by electrical and GABAergic synapses (Koós and Tepper, 1999; Gittis et al., 2010). In the neocortex, a high degree of reciprocal connectivity was described between neighboring FS and low-threshold spiking (LTS) interneurons using paired recordings (Gibson et al., 1999; Deans et al., 2001; Ma et al., 2012). Whether striatal FS interneurons target other interneuron types such as cholinergic and LTS interneurons has not been established.

Striatal cholinergic interneurons are involved in various forms of corticostriatal synaptic plasticity (Wang et al., 2006; Pisani et al., 2007) and provide the cholinergic modulation of striatal neurons and synapses (Koós and Tepper, 2002; Pakhotin and Bracci, 2007; Shen et al., 2007). As seen in vivo, they are highly synchronized (Raz et al., 1996), suggesting that they may be driven by common inhibitory input from GABAergic striatal interneurons (Sullivan et al., 2008). Paired recordings revealed no synaptic connectivity between different types of striatal interneurons (Gittis et al., 2010); however, optogenetic activation of cholinergic interneurons resulted in polysynaptic inhibition of MSNs and weaker responses in FS interneurons (English et al., 2012). Morphological reconstructions of parvalbumin-positive $(\mathrm{PV}+)$ and $\mathrm{ChAT}+$ interneurons in rat striatum indicated only unidirectional connectivity from cholinergic to PV + interneurons (Chang and Kita, 1992) although PV + synapses were reported to target cholinergic interneurons in primates (Gonzales et al., 2012). Whether and to what extent target selectivity exists 
between different classes of striatal interneurons has not been unequivocally established, largely due to the limitation of available techniques.

In this study we aimed to resolve the question of target selectivity of striatal FS interneurons by using optogenetic techniques enabling us to selectively stimulate FS interneurons while simultaneously recording from several neighboring neurons of different types.

\section{Materials and Methods}

Animals. All experiments were performed according to the Guidelines of the Stockholm municipal committee for animal experiments. PV-Cre mice (Hippenmeyer et al., 2005) of either sex $(n=49)$ were virus injected and used for slice recordings and immunohistochemical analysis $10-18 \mathrm{~d}$ after injections. To assess the direct connectivity between interneurons, we also used Lhx6-GFP BAC (bacterial artificial chromosome) transgenic mice $(n=14)$ in which FS and LTS interneurons express GFP.

Virus injections. Animals were anesthetized with isoflurane and placed in a stereotaxic frame (Harvard Apparatus). A small craniotomy was made $0.5 \mathrm{~mm}$ anterior to bregma and $2.0 \mathrm{~mm}$ lateral to the midline. Between 0.8 and $1.5 \mu \mathrm{l}$ of virus (pAAV-Ef1a-DIO-hChR2(H134R)mCherry-WPRE-pA) was injected by a micropipette at two ventral co-

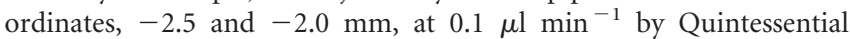
Stereotaxic Injector (Stoelting) The pipette was held in place for $5 \mathrm{~min}$ after the injection before being slowly retracted from the brain. Postinjection analgesics were given ( $0.03 \mathrm{mg} / \mathrm{kg}$ buprenorphine).

Slice preparation and whole-cell recordings. Mice at postnatal day $24-51$ were killed and used for slice recordings. They were anesthetized with isoflurane and their brains removed in ice-cold artificial CSF containing the following (in mM): $125 \mathrm{NaCl}, 25$ glucose, $25 \mathrm{NaHCO}_{3}, 2.5 \mathrm{KCl}, 2$ $\mathrm{CaCl}_{2}, 1.25 \mathrm{NaH}_{2} \mathrm{PO}_{4}, 1 \mathrm{MgCl}_{2}$. Parasagittal slices, $250 \mu \mathrm{m}$ thick, were cut (Leica VT 1000S), then transferred to $35^{\circ} \mathrm{C}$ for $30-60 \mathrm{~min}$ and then kept at room temperature $\left(22-24^{\circ} \mathrm{C}\right)$. Whole-cell patch recordings were obtained at $35 \pm 0.5^{\circ} \mathrm{C}$. Glass electrodes were pulled with a Flaming/ Brown micropipette puller P-97 (Sutter Instruments) and had a resistance of 5-10 M $\Omega$. They contained (in mM) $105 \mathrm{~K}$-gluconate, $30 \mathrm{KCl}, 10$ HEPES, $10 \mathrm{Na}$-Phosphocreatine, $4 \mathrm{Mg}$-ATP, $0.3 \mathrm{Na}$-GTP, and in some experiments $0.3 \%$ Neurobiotin. Neurons were visualized with infrared differential interference contrast (IR-DIC) microscopy (Zeiss FS Axioskop) and fluorescent microscopy, using a mercury lamp (HBO 100, Zeiss) and a fluorescent filter cube mounted on the same microscope. Pairs, triplets, and quadruplets of neurons were recorded within a range of $200 \mu \mathrm{m}$ from mCherry fluorescently labeled somata. Recordings were done in current-clamp mode with access resistance compensated throughout the experiment. Experiments with access resistance $>35 \mathrm{M} \Omega$ were discarded. Recordings were amplified using MultiClamp 700B (Molecular Devices) and digitized by an ITC-18 (HEKA Elektronik) acquisition board. Data were acquired and analyzed using IGOR Pro (WaveMetrics). Liquid junction potential was not corrected for and is approximated to be $\sim 10 \mathrm{mV}$. Photostimulation was generated through a 1 watt blue LED (wavelength $465 \mathrm{~nm}$ ) mounted on the microscope oculars and delivered through the objective lens. In a few experiments the same LED was mounted under the slice as described previously (English et al., 2012), providing illumination to the entire field. Photostimulation was controlled by a LED driver (Mightex Systems) connected to the ITC-18 acquisition board, enabling control over the duration and intensity. The photostimulation diameter through the objective lens was $\sim 400$ $\mu \mathrm{m}$ with an illumination intensity of $9 \mathrm{~mW} / \mathrm{mm}^{2}$.

Stimulation protocols and analysis. Recorded neurons were subject to various stimulation protocols to determine the synaptic and electrical properties. Synaptic connections were characterized by stimulation of a presynaptic neuron with a train $(10$ or $20 \mathrm{~Hz})$ of 8 brief current pulses $(0.5-2 \mathrm{nA}, 3 \mathrm{~ms})$ or by blue light pulses $(2 \mathrm{~ms})$. Postsynaptic neurons were held between -70 and $-80 \mathrm{mV}$ to ensure depolarizing responses to GABAergic synapses, and traces were removed for analysis when depolarized more than $-60 \mathrm{mV}$. The GABA reversal potential was approximately $-30 \mathrm{mV}$ and synaptic input could induce MSN action potential discharge when it was held just below threshold. Parameters describing the dynamics of recorded synapses included the synaptic utilization parameter ( $U$, equivalent to release probability), the time constants of recovery from depression (D) and facilitation (F). These parameters were extracted using the model for synaptic dynamics (Markram et al., 1998; Tsodyks et al., 1998; Planert et al., 2010).

Immunohistochemistry. Mice were transcardially perfused with 100 mM PBS followed by $4 \%$ formaldehyde in PBS, and brains were postfixed for $18 \mathrm{~h}$ at $4^{\circ} \mathrm{C}$. Sections of $40 \mu \mathrm{m}$ were cut using a vibratome (Leica VT1000), and free-floating sections were incubated in blocking solution ( $10 \%$ donkey serum in PBS with $0.3 \%$ Triton $\mathrm{X}-100)$ for $1 \mathrm{~h}$ at $22^{\circ} \mathrm{C}$ and then incubated with primary antibody (parvalbumin PVG-214; Swant; $1: 2000$ ) in blocking solution overnight at $22^{\circ} \mathrm{C}$. Antibody staining was revealed using species-specific fluorophore-conjugated secondary antibodies. Spread and labeling efficiency were scored for the presence of mCherry fluorescence. For quantification of colabeling of channelrhodopsin 2 (ChR2)-mCherry and parvalbumin, confocal images were acquired using confocal microscopy (Zeiss LSM 510) and individual cells were identified independently for each of the two fluorescent channels.

\section{Results}

To selectively activate striatal FS interneurons, we genetically targeted expression of ChR2 to PV+ cells. We injected an adenoassociated viral (AAV) vector, which expressed a ChR2-mCherry fusion protein in a Cre-dependent manner, into the striatum of transgenic PV-Cre mice, thereby achieving specific ChR2 expression in PV+/FS cells (Cardin et al., 2009). We targeted injections to the dorsolateral striatum and found virally transduced cells within a diameter of $300 \pm 100 \mu \mathrm{m}$. Neurons expressing mCherry-ChR2 were PV positive (97\%, Fig. $1 A)$, confirming the genetic restriction of $\mathrm{ChR} 2$ to $\mathrm{PV}+$ neurons.

We targeted whole-cell recordings to mCherry-expressing neurons using combined fluorescent and IR-DIC microscopy (Fig. 1B) and characterized the optogenetic activation of these neurons by delivering short pulses of blue light (see Materials and Methods). All neurons identified by fluorescence and depolarizing response to light stimulation were FS interneurons $(n=24$ of 24 ), as determined by their characteristic electrophysiological properties such as non-accommodating discharge pattern, high discharge rate, narrow action potentials, and fast and deep afterhyperpolarization (Fig. 1D). Interneurons responded to light pulses with strong and immediate depolarization, leading in most cases $(n=12$ of 19$)$ to action potential discharge (Fig. $1 E)$. In those cases, light pulses of $2 \mathrm{~ms}$ duration were usually sufficient to induce action potentials, enabling the stimulation of FS interneurons with trains of action potentials (Fig. $1 G$ ). Occasionally, short (2 ms) light pulses induced discharge of spike-doublets, as recorded from photostimulated FS interneurons (see example in Fig. 1G). Longer light pulses induced membrane depolarization throughout the illumination duration, indicating activation of ChR2 in recorded neurons.

To determine the precise connectivity between FS interneurons and other neuronal types within the striatal microcircuit, we characterized the synaptic connectivity of ChR2-expressing FS interneurons onto their neighboring neurons. We recorded from neurons in proximity to the ChR2-expressing FS interneurons (Fig. 2A), where the majority of nonfluorescent neurons were MSNs, as characterized by their hyperpolarized membrane potential $(-77.5 \pm 5.7 \mathrm{mV})$ and typical inward rectification response to hyperpolarizing and depolarizing current steps (Fig. $2 C)$. Most MSNs ( $n=112$ of 163) responded to brief $2 \mathrm{~ms}$ light pulses with a strong and reliable synaptic response (Fig. $2 D$ ). In a majority of the cases where a responding MSN was recorded simultaneously with a neighboring MSN, they both responded $(n=90$ of 106). In cases where MSNs did not receive synaptic 
A

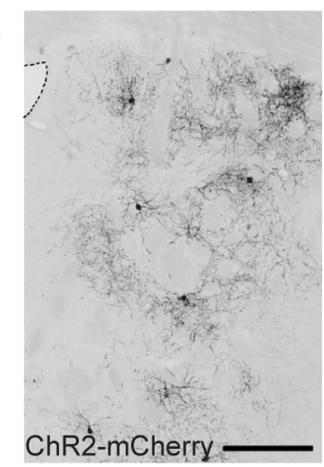

B

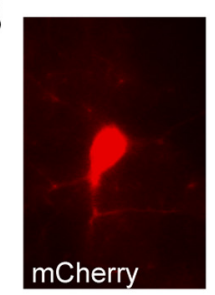

E

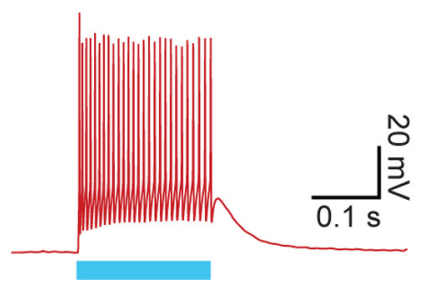

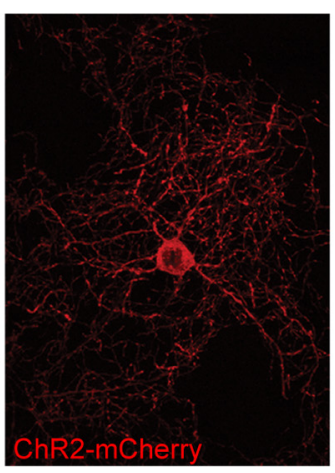
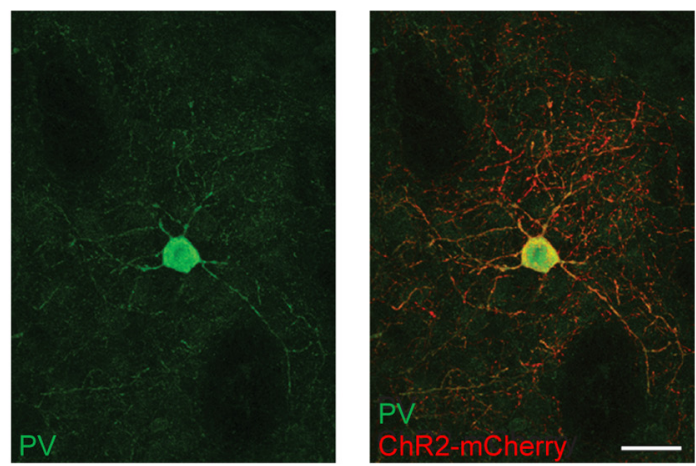

C

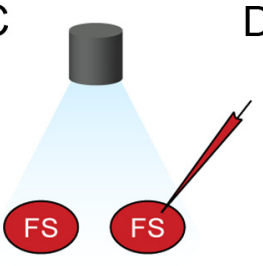

D

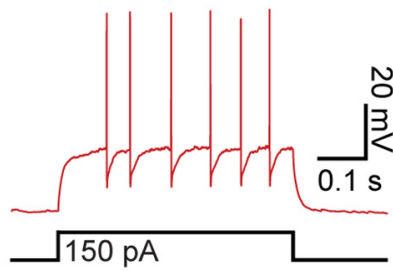

$\mathrm{F}$

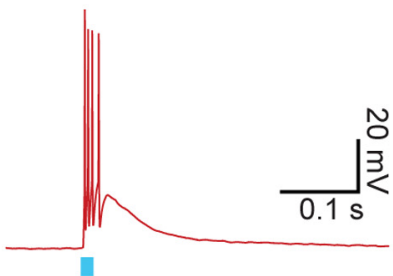

G

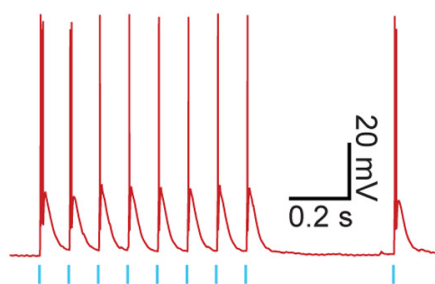

Figure 1. Optogenetic control of striatal PV-expressing FS interneurons. $A$, Confocal images of parvalbumin-expressing striatal interneurons with ChR2-mCherry expression. Overview of fluorescent image showing ChR2 (black) expression in striatal PV+ interneurons. The lateral ventricle is delineated (left). Scale bar, $250 \mu \mathrm{m}$. Magnification of a ChR2-mCherry-labeled neuron (middle left). The same neuron with PV immunostaining (middle right). Merged image demonstrating colocalization (right). Scale bar, $25 \mu \mathrm{m}$. B, A fluorescent image showing mCherry expression (left). The same interneuron visualized and recorded under IR microscopy (middle), and the merged image (right). C, Illustration of the experimental set-up with optogenetic stimulation of FS interneurons and targeted whole-cell recording. $\boldsymbol{D}$, Typical electrophysiological response of an FS interneuron to a suprathreshold step current injection. $\boldsymbol{E}$, Response of the FS interneuron to photostimulation with a single $200 \mathrm{~ms}$ pulse. $\boldsymbol{F}$, Response of the same $F S$ interneuron to a single $10 \mathrm{~ms}$ pulse. $\boldsymbol{G}$, Response of the same $F S$ interneuron to a train of light pulses (10 Hz, $2 \mathrm{~ms}$ duration). Blue bars illustrate the light stimulation period.

\section{A}

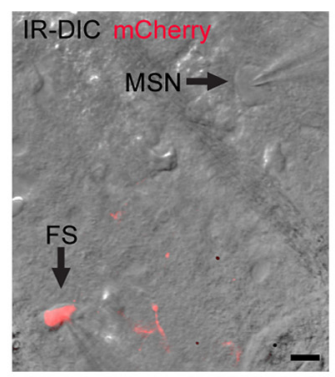

$\mathrm{D}$

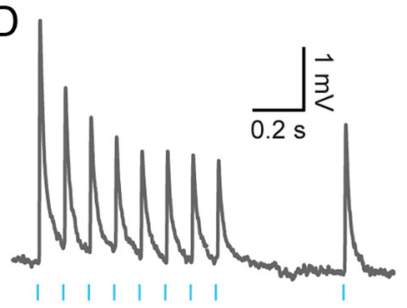

B

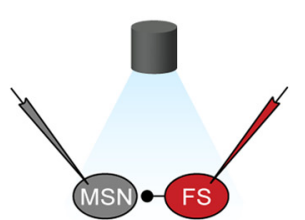

E

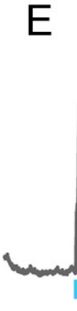

C

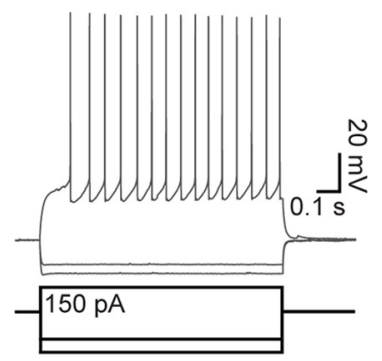

$\mathrm{F}$

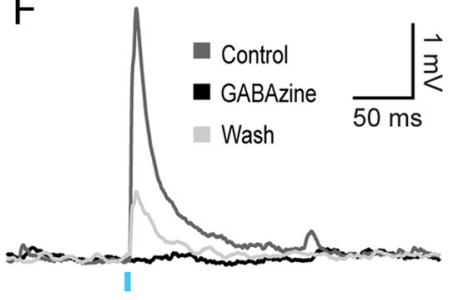

Figure 2. Light-induced feedforward inhibition from striatal PV-expressing FS interneurons onto MSNs. A, Image showing IR-DIC and fluorescent red signal during dual patching of a ChR2$\mathrm{mCherry-expressing} \mathrm{FS} \mathrm{cell} \mathrm{and} \mathrm{a} \mathrm{neighboring} \mathrm{MSN.} \mathrm{Scale} \mathrm{bar,} 10 \mu \mathrm{m} . \boldsymbol{B}$, Illustration of the experimental set-up with optogenetic stimulation and paired recording from an FS interneuron and MSN. C, Example of the electrophysiological response of an MSN to step current injections. $\boldsymbol{D}$, Depressing synaptic input to a MSN following a train of blue light pulses (10 Hz, $2 \mathrm{~ms})$. $\boldsymbol{E}$, Response of the same MSN to a 200 ms blue light pulse. F, Postsynaptic response of an MSN to optogenetic activation ( $5 \mathrm{~ms}$ ) of FS cells before, during, and after application of $10 \mu \mathrm{m}$ gabazine. The response was abolished following gabazine application and partially recovered after washout ( $n=6$ of 6 ). 

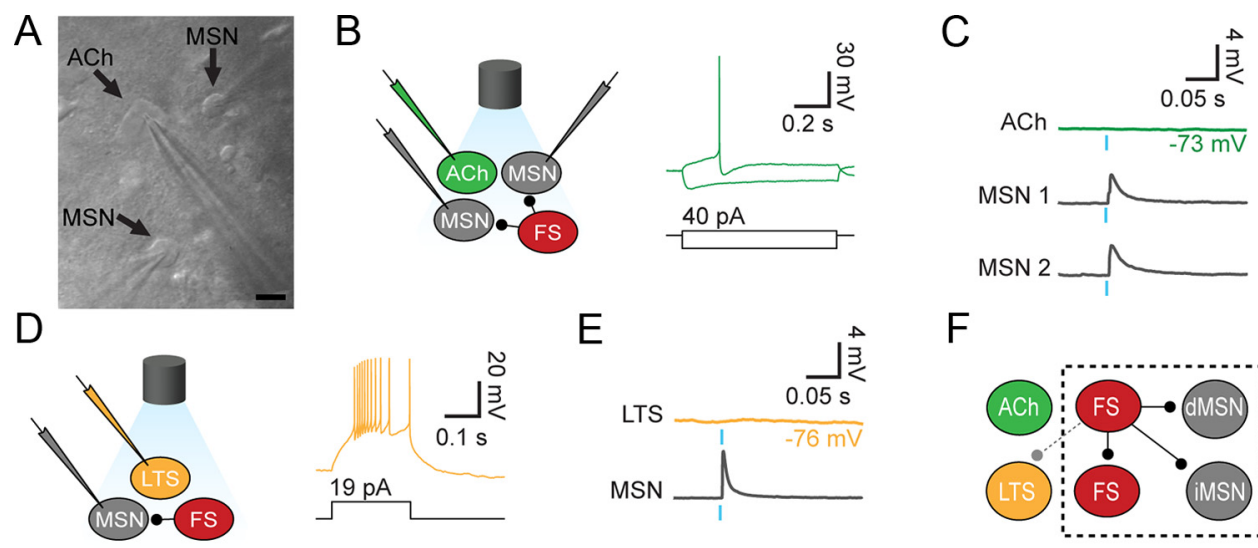

$\mathrm{F}$

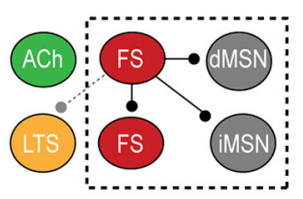

Figure 3. Target selectivity of striatal PV-expressing FS interneurons. A, Simultaneous whole-cell recording of two MSNs and a cholinergic interneuron under IR-DIC microscopy. Scale bar, $10 \mu \mathrm{m}$. $B$, Illustration of experimental set-up with optogenetic stimulation of FS cells and whole-cell recordings from two MSNs and a cholinergic interneuron (ACh). Typical electrophysiological response of a cholinergic interneuron to step current injections. C, Photostimulation of FS cells (2 ms pulse) and responses in MSNs and cholinergic interneurons. Simultaneous whole-cell recordings from cholinergic interneuron and MSNs revealed no synaptic response in the cholinergic interneuron while the neighboring MSNs received reliable synaptic input. $\boldsymbol{D}$, Illustration of experimental set-up with optogenetic stimulation of FS cells and whole-cell recordings from MSNs and LTS interneurons. Typical response of a LTS interneuron to a step current injection. $\boldsymbol{E}$, Photostimulation of FS cells (2 ms pulse) and responses in MSNs and LTS interneurons. Simultaneous whole-cell recordings from LTS interneuron and MSNs reveal no synaptic response in the LTS interneuron while a neighboring MSN shows clear responses. $\boldsymbol{F}$, Schematic model of the identified connectivity from striatal FS interneurons targeting MSNs (direct and indirect pathway MSNs) as well as neighboring FS interneurons, with sparse connectivity to LTS interneurons and none to cholinergic interneurons.

input following light stimulation, most simultaneously recorded MSNs did not receive inputs either $(n=36$ of 50$)$. These results suggest that the reason for nonresponsive MSNs was inability to induce light-evoked discharge in neighboring FS interneurons, rather than the lack of synaptic FS-MSN connectivity. The recorded light-induced synaptic responses were $\mathrm{GABA}_{\mathrm{A}}-\mathrm{R}$ dependent (Fig. 2F, $n=6$ of 6 blocked by $10 \mu \mathrm{M}$ gabazine). Lightinduced synaptic responses were more than four times larger than unitary direct connections recorded in FS-MSN pairs in the same slices $(7.5 \pm 7.4 \mathrm{mV}, n=47$ vs $1.8 \pm 1.4 \mathrm{mV} n=14, p<$ 0.001 ), suggesting that photostimulation triggered action potential discharge in several labeled FS interneurons. Stimulation with trains of light pulses (10 Hz, 2 ms, Fig. 2D) induced depressing synaptic responses, similar to previously reported direct connections between FS interneurons and MSNs (Planert et al., 2010; Gittis et al., 2011; Klaus et al., 2011). The dynamic properties of light-evoked synaptic responses were quantified using a model for synaptic dynamics (Markram et al., 1998; Tsodyks et al., 1998) (see Materials and Methods) and compared with direct FS-MSN connections recorded in the same animals ( $n=13$ synaptically connected pairs). Time constants for depression and facilitation in optical versus direct synaptic connections were similar $(p>$ $0.5, n=13$ optical and $n=11$ direct connections); however, the release probability (utilization factor, $\mathrm{U}$ ) was higher in the lightinduced responses ( $\mathrm{U}=0.59 \pm 0.18$ vs $0.46 \pm 0.06, p=0.03$ ), apparent also in a smaller paired-pulse ratio in light-induced responses compared with direct connections $(0.65 \pm 0.22$ vs $0.84 \pm 0.19, p=0.03)$. This apparent difference in synaptic release is likely to be caused by the doublets of action potentials observed in some cases (for example Fig. $1 G$ ), also described previously for the activation of ChR2 (Gunaydin et al., 2010).

To study the synaptic connectivity from FS interneurons to other types of striatal interneurons, we recorded from cholinergic and LTS interneurons during photostimulation of ChR2expressing FS cells. To confirm the proper optogenetic light activation of FS interneurons and their synaptic transmission at the recording area, we simultaneously recorded from pairs or triplets of neurons, in which at least one MSN or FS interneuron exhibited light-induced synaptic responses or action potentials, re- spectively (Fig. 3). Cholinergic interneurons were identified using typical morphological and electrophysiological properties, including large soma, depolarized membrane potential ( $-53.0 \pm$ $5.6 \mathrm{mV}$ ), voltage sag response, and pronounced discharge accommodation (Fig. 3B). Interestingly, cholinergic interneurons $(n=$ 13) did not show any synaptic events following light activation of ChR2-expressing FS interneurons, in contrast to the simultaneous strong and reliable synaptic response recorded at nearby $(<100 \mu \mathrm{m})$ MSNs $(n=13$ of 13, Fig. $3 C)$. We also recorded from LTS interneurons, characterized by their high input resistance $(471 \pm 170 \mathrm{M} \Omega)$, lower action potential discharge threshold $(-47.3 \pm 2.4 \mathrm{mV})$, depolarized membrane potential $(-44 \pm 5$ $\mathrm{mV}$ ), long membrane time constant ( $21 \pm 7 \mathrm{~ms}$ ), and accommodating discharge to a step current injection (Fig. 3D). Most LTS interneurons ( $n=4$ of 5$)$ did not receive any synaptic inputs following photostimulation of FS interneurons, while the neighboring neurons recorded simultaneously all responded, suggesting that LTS interneurons are only sparsely targeted by neighboring FS cells (Fig. 3E). The single LTS that responded to optogenetic stimulation displayed relatively weak responses $(2.1 \mathrm{mV})$, compared with large responses recorded from two neighboring MSNs (9.6 and $6.9 \mathrm{mV}$ ). To further assess the connectivity between FS and LTS interneurons, we recorded from pairs of FS and LTS interneurons. To facilitate interneuron recordings we used Lhx6-GFP transgenic mice in which LTS and FS interneurons are fluorescently labeled (Gittis et al., 2010). Indeed, from 12 tested FS-LTS pairs we found only two, weak $(0.5$ and $0.8 \mathrm{mV}$ ) synaptic connections, both from FS to LTS, further supporting the results obtained by optogenetic stimulation.

In summary, our work has identified that feedforward inhibition from striatal FS interneurons is highly selective, reliably targeting MSNs and FS interneurons while avoiding cholinergic interneurons and only sparsely contacting LTS interneurons (schematic in Fig. 3F).

\section{Discussion}

In this study we showed that feedforward inhibition exerted by striatal FS interneurons is not promiscuous but highly selective in terms of postsynaptic targets. FS interneurons contact neighboring MSNs with high probability providing strong and reliable 
inhibition, while cholinergic interneurons are avoided and LTS interneurons are contacted only with low probability. Interestingly, neocortical FS interneurons display a similar targeting pattern onto pyramidal neurons (Somogyi et al., 1998; Gupta et al., 2000; Packer and Yuste, 2011), while also forming reciprocal electrical and chemical connections with each other (Galarreta and Hestrin, 1999; Gibson et al., 1999). Both striatal and neocortical projection neurons are sparsely interconnected, with a minority of neighboring neurons forming synaptic connections (Markram et al., 1997; Czubayko and Plenz, 2002; Tunstall et al., 2002; Taverna et al., 2008; Brown and Hestrin, 2009; Planert et al., 2010). In contrast, connectivity from FS interneurons onto projection neurons is robust and widespread (Koós and Tepper, 1999; Gittis et al., 2010; Gittis et al., 2011; Packer and Yuste, 2011).

Despite the similar electrophysiological properties between cortical and striatal FS and LTS interneurons (Kubota and Kawaguchi, 1994; Kawaguchi and Kubota, 1997), there are important differences in microcircuit architecture. First, unlike striatum, neocortical FS interneurons form reciprocal connections with LTS interneurons (Gibson et al., 1999; Deans et al., 2001; Cruikshank et al., 2010) and other interneuron types (Staiger et al., 1997; Gupta et al., 2000; Avermann et al., 2012). Second, the dominant reciprocal connectivity between neocortical interneurons and projection neurons (Reyes et al., 1998; Beierlein et al., 2003; Holmgren et al., 2003; Silberberg and Markram, 2007) is not found in striatum, where feedforward inhibition from FS onto MSNs is unidirectional (Koós and Tepper, 1999; Gittis et al., 2010; Planert et al., 2010; Chuhma et al., 2011). The degree of target selectivity of cortical FS interneurons within cortical microcircuits is not fully characterized and it remains to be seen whether it follows similar rules as in the striatal microcircuitry.

Our results show no functional synaptic connectivity from striatal PV + to cholinergic interneurons. While in agreement with previous anatomical results from rat striatum (Chang and Kita, 1992), there is an apparent discrepancy with recent data from macaque monkey putamen, where PV + terminals were shown to form symmetric synapses with dendrites of cholinergic neurons (Gonzales et al., 2012). There are a few possible explanations to this discrepancy. First, the symmetric PV + terminals may originate from pallidostriatal axons (Kita et al., 1999; Mallet et al., 2012), which would therefore not be infected by the viral injection in the striatum. Second, the reported cholinergic neurons were targeted on distal dendrites, which may result in electrotonic attenuation in our somatic recordings. Third, the contrasting findings may indicate differences between the studied species, which would also explain the differences between the two aforementioned anatomical studies (Chang and Kita, 1992; Gonzales et al., 2012).

\section{Functional implications}

The selectivity in FS interneuron feedforward inhibition suggests independent roles for different interneuron types in sculpting striatal output. The striatum receives convergent input from various sources such as glutamatergic inputs from cortex and thalamus (Dubé et al., 1988; Thomas et al., 2000; Ding et al., 2008; Doig et al., 2010), dopaminergic inputs from the substantia nigra pars compacta, and GABAergic inputs from the globus pallidus (Bevan et al., 1998; Mallet et al., 2012). The way these inputs orchestrate striatal output depends not only on their direct projections onto MSNs but also on their connectivity onto different interneuron types. The avoidance of cholinergic interneurons suggests that their correlation in pauses and discharge (Raz et al., 1996) is not generated by FS-mediated feedforward inhibition.
MSNs therefore receive independent streams of feedforward inhibition, one of which is mediated by FS interneurons (Koós and Tepper, 1999; Gage et al., 2010), another provided by cholinergic interneurons (English et al., 2012), in addition to the lateral inhibition between MSNs (Tunstall et al., 2002) and pallidal input (Mallet et al., 2012). This richness of GABAergic pathways is crucial for the differential sculpting of striatal output under a variety of conditions and brain states.

\section{References}

Avermann M, Tomm C, Mateo C, Gerstner W, Petersen CC (2012) Microcircuits of excitatory and inhibitory neurons in layer $2 / 3$ of mouse barrel cortex. J Neurophysiol 107:3116-3134. CrossRef Medline

Beierlein M, Gibson JR, Connors BW (2003) Two dynamically distinct inhibitory networks in layer 4 of the neocortex. J Neurophysiol 90: 2987-3000. CrossRef Medline

Bennett BD, Bolam JP (1994) Synaptic input and output of parvalbuminimmunoreactive neurons in the neostriatum of the rat. Neuroscience 62:707-719. CrossRef Medline

Bevan MD, Booth PA, Eaton SA, Bolam JP (1998) Selective innervation of neostriatal interneurons by a subclass of neuron in the globus pallidus of the rat. J Neurosci 18:9438-9452. Medline

Brown SP, Hestrin S (2009) Intracortical circuits of pyramidal neurons reflect their long-range axonal targets. Nature 457:1133-1136. CrossRef Medline

Cardin JA, Carlén M, Meletis K, Knoblich U, Zhang F, Deisseroth K, Tsai LH, Moore CI (2009) Driving fast-spiking cells induces gamma rhythm and controls sensory responses. Nature 459:663-667. CrossRef Medline

Chang HT, Kita H (1992) Interneurons in the rat striatum: relationships between parvalbumin neurons and cholinergic neurons. Brain Res 574: 307-311. CrossRef Medline

Chuhma N, Tanaka KF, Hen R, Rayport S (2011) Functional connectome of the striatal medium spiny neuron. J Neurosci 31:1183-1192. CrossRef Medline

Cruikshank SJ, Urabe H, Nurmikko AV, Connors BW (2010) Pathwayspecific feedforward circuits between thalamus and neocortex revealed by selective optical stimulation of axons. Neuron 65:230-245. CrossRef Medline

Czubayko U, Plenz D (2002) Fast synaptic transmission between striatal spiny projection neurons. Proc Natl Acad Sci U S A 99:15764-15769. CrossRef Medline

Deans MR, Gibson JR, Sellitto C, Connors BW, Paul DL (2001) Synchronous activity of inhibitory networks in neocortex requires electrical synapses containing connexin36. Neuron 31:477-485. CrossRef Medline

Ding J, Peterson JD, Surmeier DJ (2008) Corticostriatal and thalamostriatal synapses have distinctive properties. J Neurosci 28:6483-6492. CrossRef Medline

Doig NM, Moss J, Bolam JP (2010) Cortical and thalamic innervation of direct and indirect pathway medium-sized spiny neurons in mouse striatum. J Neurosci 30:14610-14618. CrossRef Medline

Dubé L, Smith AD, Bolam JP (1988) Identification of synaptic terminals of thalamic or cortical origin in contact with distinct medium-size spiny neurons in the rat neostriatum. J Comp Neurol 267:455-471. CrossRef Medline

English DF, Ibanez-Sandoval O, Stark E, Tecuapetla F, Buzsáki G, Deisseroth K, Tepper JM, Koos T (2012) GABAergic circuits mediate the reinforcement-related signals of striatal cholinergic interneurons. Nat Neurosci 15:123-130. CrossRef Medline

Gage GJ, Stoetzner CR, Wiltschko AB, Berke JD (2010) Selective activation of striatal fast-spiking interneurons during choice execution. Neuron 67: 466-479. CrossRef Medline

Galarreta M, Hestrin S (1999) A network of fast-spiking cells in the neocortex connected by electrical synapses. Nature 402:72-75. CrossRef Medline

Gibson JR, Beierlein M, Connors BW (1999) Two networks of electrically coupled inhibitory neurons in neocortex. Nature 402:75-79. CrossRef Medline

Gittis AH, Nelson AB, Thwin MT, Palop JJ, Kreitzer AC (2010) Distinct roles of GABAergic interneurons in the regulation of striatal output pathways. J Neurosci 30:2223-2234. CrossRef Medline

Gittis AH, Hang GB, LaDow ES, Shoenfeld LR, Atallah BV, Finkbeiner S, Kreitzer AC (2011) Rapid target-specific remodeling of fast-spiking in- 
hibitory circuits after loss of dopamine. Neuron 71:858-868. CrossRef Medline

Gonzales KK, Pare JF, Wichmann T, Smith Y (2012) GABAergic regulation of striatal cholinergic interneurons: synaptic inputs from fastforward parvalbumin-containing interneurons. Soc Neurosci Abstr 38:790.07.

Gunaydin LA, Yizhar O, Berndt A, Sohal VS, Deisseroth K, Hegemann P (2010) Ultrafast optogenetic control. Nat Neurosci 13:387-392. CrossRef Medline

Gupta A, Wang Y, Markram H (2000) Organizing principles for a diversity of GABAergic interneurons and synapses in the neocortex. Science 287: 273-278. CrossRef Medline

Hippenmeyer S, Vrieseling E, Sigrist M, Portmann T, Laengle C, Ladle DR, Arber S (2005) A developmental switch in the response of DRG neurons to ETS transcription factor signaling. PLoS Biol 3:e159. CrossRef Medline

Holmgren C, Harkany T, Svennenfors B, Zilberter Y (2003) Pyramidal cell communication within local networks in layer $2 / 3$ of rat neocortex. J Physiol 551:139-153. CrossRef Medline

Kawaguchi Y, Kubota Y (1997) GABAergic cell subtypes and their synaptic connections in rat frontal cortex. Cereb Cortex 7:476-486. CrossRef Medline

Kawaguchi Y, Wilson CJ, Augood SJ, Emson PC (1995) Striatal interneurones: chemical, physiological and morphological characterization. Trends Neurosci 18:527-535. CrossRef Medline

Kita H, Kosaka T, Heizmann CW (1990) Parvalbumin-immunoreactive neurons in the rat neostriatum: a light and electron microscopic study. Brain Res 536:1-15. CrossRef Medline

Kita H, Tokuno H, Nambu A (1999) Monkey globus pallidus external segment neurons projecting to the neostriatum. Neuroreport 10:1467-1472. CrossRef Medline

Klaus A, Planert H, Hjorth JJ, Berke JD, Silberberg G, Kotaleski JH (2011) Striatal fast-spiking interneurons: from firing patterns to postsynaptic impact. Front Syst Neurosci 5:57. Medline

Koós T, Tepper JM (1999) Inhibitory control of neostriatal projection neurons by GABAergic interneurons. Nat Neurosci 2:467-472. CrossRef Medline

Koós T, Tepper JM (2002) Dual cholinergic control of fast-spiking interneurons in the neostriatum. J Neurosci 22:529-535. Medline

Kubota Y, Kawaguchi Y (1994) Three classes of GABAergic interneurons in neocortex and neostriatum. Jpn J Physiol 44[Suppl 2]:S145-S148.

Ma Y, Hu H, Agmon A (2012) Short-term plasticity of unitary inhibitoryto-inhibitory synapses depends on the presynaptic interneuron subtype. J Neurosci 32:983-988. CrossRef Medline

Mallet N, Micklem BR, Henny P, Brown MT, Williams C, Bolam JP, Nakamura KC, Magill PJ (2012) Dichotomous organization of the external globus pallidus. Neuron 74:1075-1086. CrossRef Medline

Markram H, Lübke J, Frotscher M, Roth A, Sakmann B (1997) Physiology and anatomy of synaptic connections between thick tufted pyramidal neurones in the developing rat neocortex. J Physiol 500:409-440. Medline

Markram H, Wang Y, Tsodyks M (1998) Differential signaling via the same axon of neocortical pyramidal neurons. Proc Natl Acad Sci U S A 95: 5323-5328. CrossRef Medline

Markram H, Toledo-Rodriguez M, Wang Y, Gupta A, Silberberg G, Wu C (2004) Interneurons of the neocortical inhibitory system. Nat Rev Neurosci 5:793-807. CrossRef Medline
Packer AM, Yuste R (2011) Dense, unspecific connectivity of neocortical parvalbumin-positive interneurons: a canonical microcircuit for inhibition? J Neurosci 31:13260-13271. CrossRef Medline

Pakhotin P, Bracci E (2007) Cholinergic interneurons control the excitatory input to the striatum. J Neurosci 27:391-400. CrossRef Medline

Pisani A, Bernardi G, Ding J, Surmeier DJ (2007) Re-emergence of striatal cholinergic interneurons in movement disorders. Trends Neurosci 30: 545-553. CrossRef Medline

Planert H, Szydlowski SN, Hjorth JJ, Grillner S, Silberberg G (2010) Dynamics of synaptic transmission between fast-spiking interneurons and striatal projection neurons of the direct and indirect pathways. J Neurosci 30:3499-3507. CrossRef Medline

Raz A, Feingold A, Zelanskaya V, Vaadia E, Bergman H (1996) Neuronal synchronization of tonically active neurons in the striatum of normal and parkinsonian primates. J Neurophysiol 76:2083-2088. Medline

Reyes A, Lujan R, Rozov A, Burnashev N, Somogyi P, Sakmann B (1998) Target-cell-specific facilitation and depression in neocortical circuits. Nat Neurosci 1:279-285. CrossRef Medline

Shen W, Tian X, Day M, Ulrich S, Tkatch T, Nathanson NM, Surmeier DJ (2007) Cholinergic modulation of Kir2 channels selectively elevates dendritic excitability in striatopallidal neurons. Nat Neurosci 10:1458-1466. CrossRef Medline

Silberberg G, Markram H (2007) Disynaptic inhibition between neocortical pyramidal cells mediated by Martinotti cells. Neuron 53:735-746. CrossRef Medline

Somogyi P, Tamás G, Lujan R, Buhl EH (1998) Salient features of synaptic organisation in the cerebral cortex. Brain Res Brain Res Rev 26:113-135. Medline

Staiger JF, Freund TF, Zilles K (1997) Interneurons immunoreactive for vasoactive intestinal polypeptide (VIP) are extensively innervated by parvalbumin-containing boutons in rat primary somatosensory cortex. Eur J Neurosci 9:2259-2268. CrossRef Medline

Sullivan MA, Chen H, Morikawa H (2008) Recurrent inhibitory network among striatal cholinergic interneurons. J Neurosci 28:8682-8690. CrossRef Medline

Tamás G, Buhl EH, Lörincz A, Somogyi P (2000) Proximally targeted GABAergic synapses and gap junctions synchronize cortical interneurons. Nat Neurosci 3:366-371. CrossRef Medline

Taverna S, Ilijic E, Surmeier DJ (2008) Recurrent collateral connections of striatal medium spiny neurons are disrupted in models of Parkinson's disease. J Neurosci 28:5504-5512. CrossRef Medline

Thomas TM, Smith Y, Levey AI, Hersch SM (2000) Cortical inputs to m2immunoreactive striatal interneurons in rat and monkey. Synapse 37: 252-261. CrossRef Medline

Tsodyks M, Pawelzik K, Markram H (1998) Neural networks with dynamic synapses. Neural Comput 10:821-835. CrossRef Medline

Tunstall MJ, Oorschot DE, Kean A, Wickens JR (2002) Inhibitory interactions between spiny projection neurons in the rat striatum. J Neurophysiol 88:1263-1269. Medline

Wang Z, Kai L, Day M, Ronesi J, Yin HH, Ding J, Tkatch T, Lovinger DM, Surmeier DJ (2006) Dopaminergic control of corticostriatal long-term synaptic depression in medium spiny neurons is mediated by cholinergic interneurons. Neuron 50:443-452. CrossRef Medline 